\title{
A new species of cockroach, Periplaneta gajajimana sp. nov., collected in Gajajima, Kagoshima Prefecture, Japan
}

\author{
Komatsu, N. ${ }^{1}$, lio, H. $^{2}$, Ooi, H.K. ${ }^{3 *}$ \\ ${ }^{1}$ Civil International Corporation, 10-14 Kitaueno 1, Taito-ku, Tokyo, 110-0014, Japan \\ ${ }^{2}$ Foundation for the Protection of Deer in Nara, 160-1 Kasugano-cho, Nara-City, Nara, 630-8212, Japan \\ ${ }^{3}$ Laboratory of Parasitology, School of Veterinary Medicine, Azabu University, 1-17-710 Fuchinobe, Sagamihara, Kanagawa $252-5201$ Japan \\ *Corresponding author: hkooi@azabu-u.ac.jp
}

\section{ARTICLE HISTORY}

Received: 25 January 2021

Revised: 2 February 2021

Accepted: 2 February 2021

Published: 30 April 2021

\begin{abstract}
We described a new species of cockroach, Periplaneta gajajimana sp. nov., which was collected in Gajajima, Kagoshima-gun Toshimamura, Kagoshima Prefecture, Japan, on November 2012. The new species is characterized by its reddish brown to blackish brown body, smooth surface pronotum, well developed compound eyes, dark brown head apex, dark reddish brown front face and small white ocelli connected to the antennal sockets. In male, the tegmen tip reach the abdomen end or are slightly shorter, while in the female, it does not reach the abdominal end and exposes the abdomen beyond the $7^{\text {th }}$ abdominal plate. We confirmed the validity of this new species by breeding the specimens in our laboratory to demonstrate that the features of the progeny were maintained for several generations. For comparison and easy identification of this new species, the key to species identification of the genus Periplaneta that had been reported in Japan to date are also presented.
\end{abstract}

Keywords: Cockroach; Periplaneta gajajimana; new species; Japan; Key to species.

\section{INTRODUCTION}

The genus Periplaneta was created by Burmeister, 1838, and Princis $(1966,1971)$ considered Hebardina formosana (Karny, $1915)$ as the synonym of $P$. karnyi Shiraki, 1931. The number of species in this genus has been recorded to be 49 worldwide. Kumar (1975) changed Premethana robusta (Shelford, 1909) and P. stygia (Shelford, 1909) to the genus Periplaneta. Later, Asahina (1977) reported a new species of $P$. suzukii Asahina, 1977, followed by the publication of $P$. uenoi, Asahina, 1980. He also placed the genus Cartoblatta into Periplaneta by renaming two species as P. arisanica Shiraki, 1931 and P. formosana Karny, 1915. However, Bohn (1984) transferred P. furcate (Karny, 1908) into the genus Blatta. Nevertheless, Roth (1994) recorded $P$. aboriginea Roth, 1994 in Australia. Roth (1999) considered $P$. svenhedini as a synonym of $P$. uenoi, Asahina, 1980, resulting in the 53 known species. We present in this paper a new species of Periplaneta, namely P. gajajimana, from Japan. For comparison and easy identification of this new species, the key to species identification of the genus Periplaneta reported to date in Japan are also presented. These include P. australasiae, P. brunnea, P. americana, P. suzukii, P. japonica, $P$. fuliginosa and $P$. japanna.

\section{MATERIALS AND METHODS}

The specimens were collected from Gajajima (N29.9014843 E129.5432265, 30m elevation above sea-level), Kagoshima-gun
Toshimamura, Kagoshima Prefecture, Japan (Figure 1) on November 9, 2012. The Amami region, which includes Gajajima, has a subtropical oceanic climate with warm and humid weather throughout the four seasons, and an annual average temperature of over $20^{\circ} \mathrm{C}$. The vegetation of the island is dominated by evergreen broad-leaved trees. Six juvenile cockroaches were collected under the bark of a fallen tree by the roadside during daytime. The juveniles were reared in the laboratory until they became adults.

The cockroaches were reared in the laboratory according to the method described by Komatsu et al. (2014) and had been passaged for more than five generations to confirm the morphological phenotype of the progeny. Briefly, the cockroaches were reared in a plastic container of diameter $90 \mathrm{~mm}$ and a height of $50 \mathrm{~mm}$. Beddings consist of $10 \mathrm{~mm}$ thick hydrated insect-rearing mat (Fujicon Co., Japan) and holes were made in the container lid for aeration. The cockroaches were fed carrot slices cut to $10 \mathrm{~mm}$ thickness. The whole container was placed in an incubator (Sanyo Co., Japan), with temperature set at $26-28^{\circ} \mathrm{C}$, humidity at $50-70 \%$ and left under natural light condition (Light: Darkness, $14 \mathrm{hr}: 10 \mathrm{hr}$ in summer; $10 \mathrm{hr}: 14 \mathrm{hr}$ in winter). The rearing-mat and the carrots were replaced at appropriate time to prevent the growth of fungus. To confirm the validity of this new species, the cockroaches were bred for at least five generations and the features of their progeny were observed.

To observe the minute details of their reproductive organs, the cockroaches were killed in $70 \%$ ethanol and then 


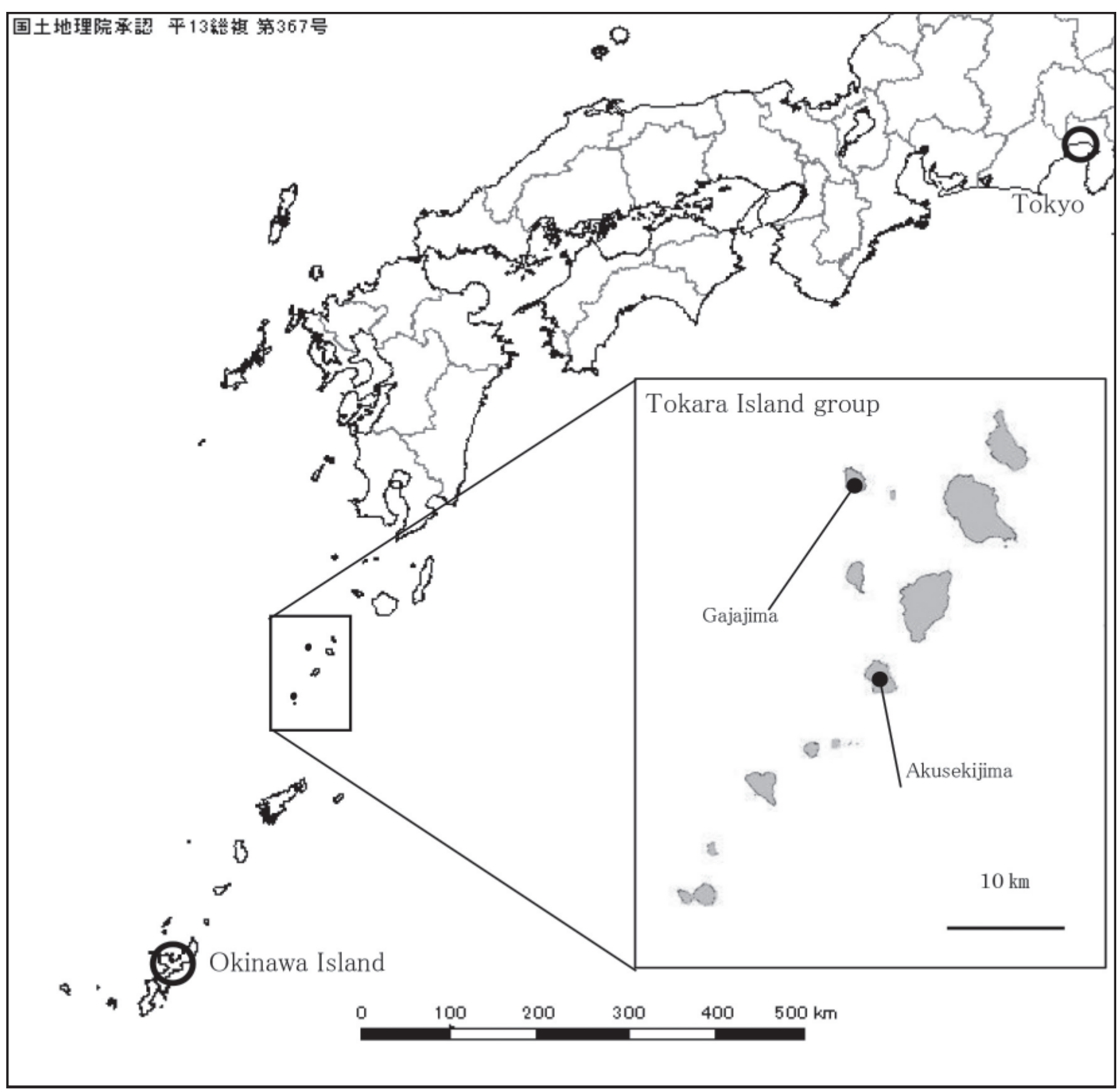

Figure 1. Map showing the location of Gajajima and Akusekijima in the Tokara island group, Japan, where the cockroaches were collected.

cleared for 24 hours in $10 \%$ potassium hydroxide. They were then mounted in Neo-cigaral solution (Shiga Konchuu Fukyusha, (Shiga Entomological Supply Co.) Japan) for microscopic examination. Morphometrical comparison of the specimens were carried out with those of $P$. japanna Asahina, 1977, that were collected by Akihiro Sonobe from Kume-jima, Okinawa, and also with $P$. fuliginosa Serville,1838, that were collected in Taito ward, Tokyo. Nomenclature of the reproductive organs and taxonomical terms used follow that of Roth (2003).

\section{RESULTS}

\section{Genus Periplaneta Burmeister}

Male and female adults of the genus Periplaneta are generally of the same size. Antennae are slim and longer than body length. The pronotum is trapezoidal with a slight bulge in the center and the side edge tapered off. The back of the head is almost covered by the pronotum. The lateral edge of the mesonotum and metanotum does not taper off like a membrane. Both tegmen and hindwings are well developed and in the male, the terminal of the wings extend beyond the abdominal end. In the females, the wings are slightly shorter than the males, and in some species they have short wings that truncated at half way of the abdomen. In the long wing form, the hindwings are well developed, and anterior part of the RP branch is quite wide. The cercus is long and male subgenital plate is symmetrical. From the lateral invagination, exude a symmetrically long pair of style. The legs are long and thin. The anterior lower edge of the femur of the fore leg has a row of long spines. The spines at the basal part are rather long, and the terminal has three long coarse spines. The lower edge of the middle and hind legs 
has stout and long spines. The tarsus is exceptionally long, and there is a small flap-like structure at the tip of the 4th segment. The arolium has a truncated shape (Asahina, 1991).

\section{Periplaneta gajajimana sp. nov.}

[Japanese name: Tsuyaaka- gokiburi]

Specimens were originally collected at Gajajima, Kagoshima-gun Toshimamura, Kagoshima Prefecture Japan, on November 9, 2012. The specimens were deposited at the Tsukuba branch of the National Museum of Nature and Science, Japan, with the following accession number: Holotype, NSMT-I-Dct-14; Allotype, NSMT-I-Dct-15 and Paratype, NSMT-I-Dct-16 \&17.

The body of both male and female are basically glossy dark reddish brown, but changes greatly, depending on the individual, with some having dark black or dark red color. Males and females are of the same size. Abdomen of the male is slim and long, and the wings terminate at the abdominal end. Abdomen of female is stout and broad, and the wing do not reach the abdominal end, leaving the abdomen exposed by about one-fifth of its length (Figure 2). Compound eyes are well developed, the apex of the head is dark brown and the front face is dark reddish brown. Ocelli is white, conspicuous but small and connected to the antennal sockets (Figure 3-A). Antennae slim and longer than body length. Pronotum is large trapezoid, reddish brown to black with a light reddish brown spot at the center (Figure 3$B)$. The head does not protrude from the pronotum. Tegmen well developed, dark reddish brown, and in the male, they slightly exceed the abdominal end. In the female, the tegmen is shorter than the male and does not reach the abdominal end.

The subgenital plate of the male has a gentle curved surface with invagination at the edge forming two undulating crests. From the depressions on both sides, a pair of style with slightly enlarged at the central part but thin at both the base and the terminal, could be seen protruding, one to the left and the other to the right. The subgenital plate is dark reddish brown with many stipples (Fig. $3-\mathrm{C}$ ). The supra-anal plate of the male is rectangular but with rounded corners and the central part is slightly curved and dented inwards (Fig. 3-D). The femur of the fore leg show an A type structure with 16 spines including the apical spine (Fig. 3-E). The femur of the middle and hind legs each has a row of eight spines.
In the male, there is an attraction hormone gland opening at in the center of the first abdominal segment (Fig. 3-F). In the male genitalia, the spines at the tip of $L 2 v$ are short (Fig. 3-G). R1 has two key-like hooks and R3 is small (Fig. $3-H)$. The tip of R3d of male genitalia is straight without any curve (Fig. $3-I$ ). In the female, the supra-anal plate is triangular and concave at the central part (Fig. 3-J). The female subgenital plate is sharply divided vertically (Fig. 3-K).

Measurements ( $\mathrm{mm}$; female in parentheses): Length, 25 27 (17 19); pronotum length $\mathrm{x}$ width 6.2 6.7 x 8.2 9.0 (7.5 7.9 x 9.6 9.9); wing length: 17.2 19.1 (16.2 18.2).

The validity of this new species was confirmed in the progeny which showed the same morphological features after breeding for at least five generations in the laboratory. It took about one year to breed one generation of this species under the conditions described above. Specimens were also collected at Akusekijima, Kagoshima-gun Toshimamura, Kagoshima Prefecture Japan, on December 2, 2018

\section{DISCUSSION}

P. gajajimana is quite similar to $P$. fuliginosa Serville, 1838 , and P. japanna Asahina, 1969 that are also found in Japan. The body colour of both $P$. fuliginosa and $P$. gajajimana are also smoky brown. However, in P. gajajimana, wings of both male and female adults are short, with the tegmen of the male just covering the posterior tip of the abdomen, and that of the female was much shorter and the abdomen was exposed. Moreover, there is no deep " $V$ " invagination at posterior edge of the supra-anal plate of the male, but only showing a shallow invagination on an oval edge. The cerci of $P$. gajajimana are short and stout.

The supra-anal plate of both species has large protruding quadrangular sides, but in $P$. fuliginosa, it protrudes with a sharp tip angle at the peripheral corner. In $P$. gajajimana, the supra anal plate has a curved corner. The number of spines on the femur of the fore leg are the same in both species but the spines at the base are shorter for $P$. gajajimana. In P. gajajimana, L2d of the male genitalia ends linearly as compared to $P$. fuliginosa, and the spines at the tip of L2V are shorter. Moreover, it is easy to distinguish R1 of P. gajajimana because the tip structure is three-dimensional, with each tip being rounded and does not point like a sword.

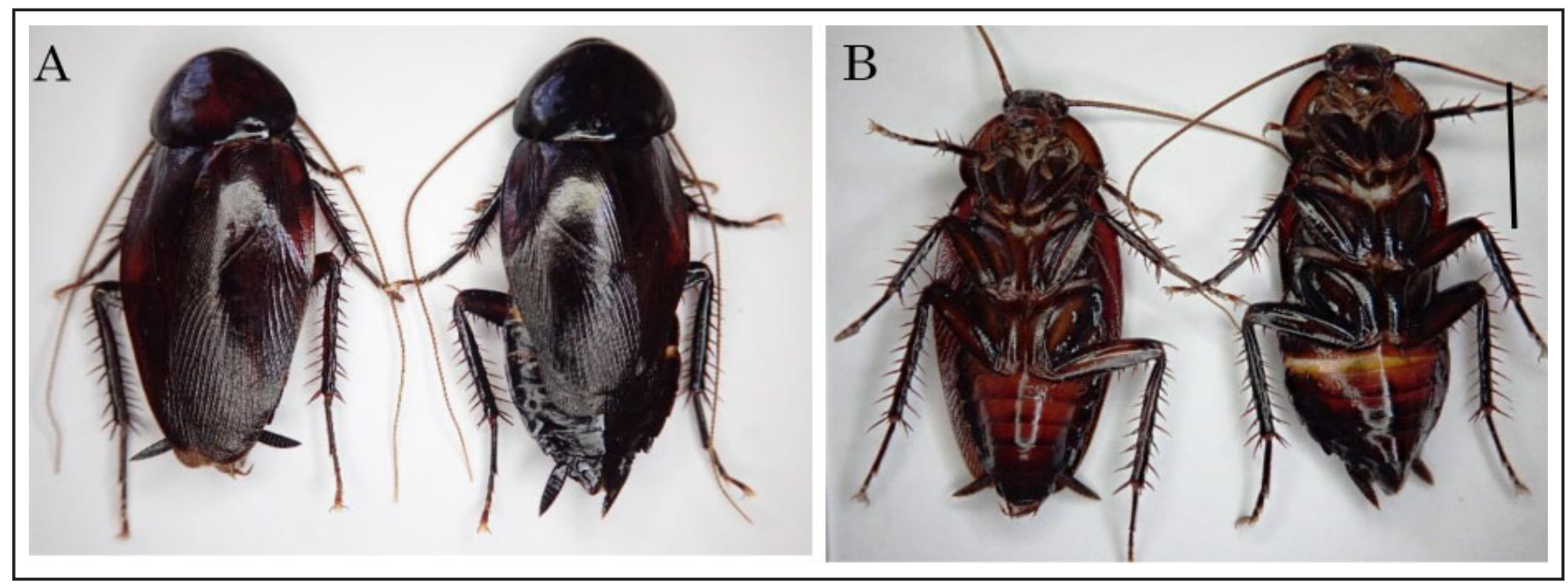

Figure 2. Periplaneta gajajimana sp. nov., life pictures. A: Left, Male. Right, Female (dorsal view). B: Left, Male. Right, Female (ventral view). Scale bar $10 \mathrm{~mm}$. 


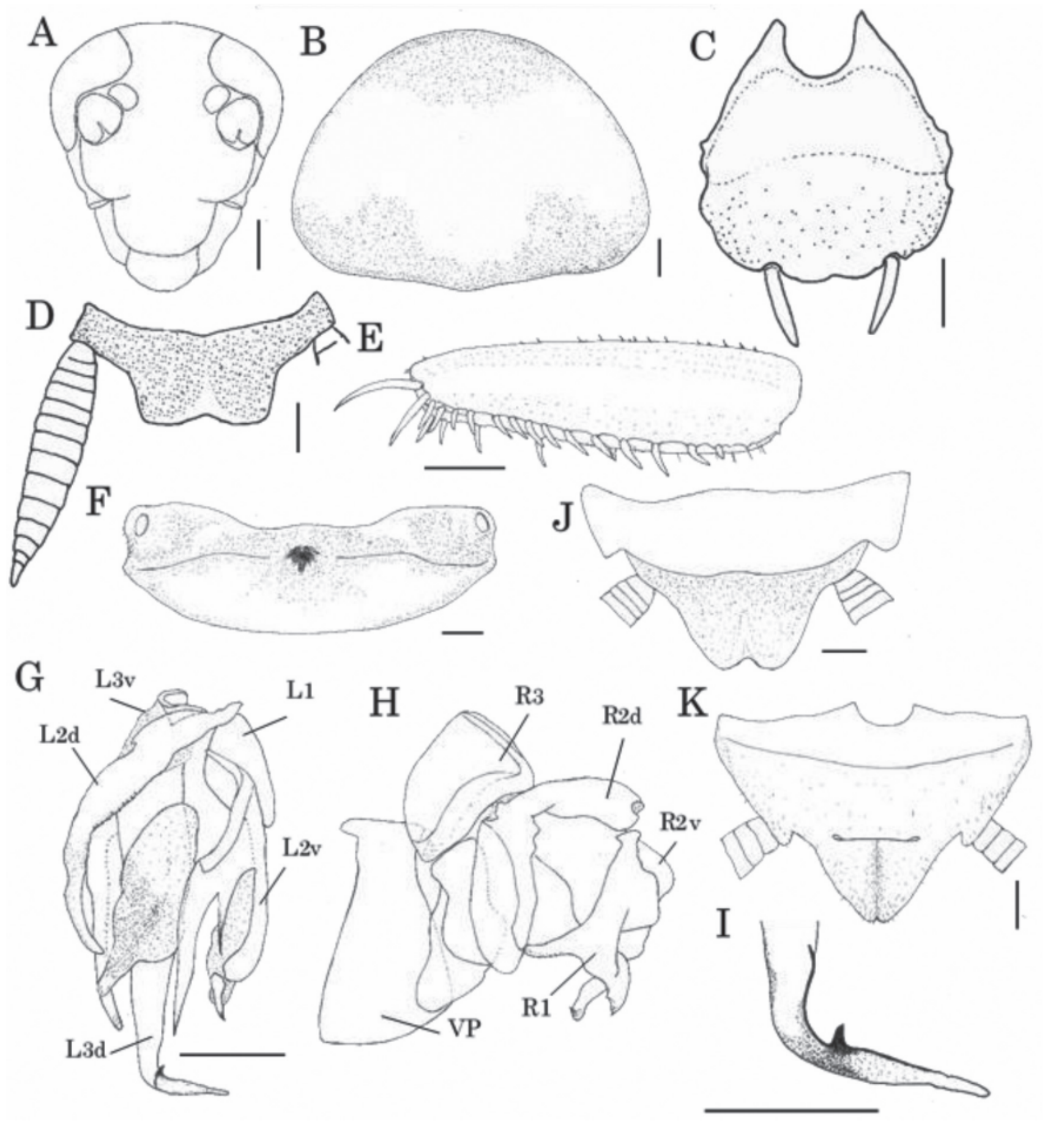

Figure 3. Periplaneta gajajimana sp. nov., male (A-I) and female (J- K). A- facial part of head; B- pronotum; C- subgenital plate, ventral view; D- supra-anal plate, dorsal view; E- front femur; F- abdomimal tergum 1, dorsal view; G- left phallomere ventral view; H- right phallomere ventral view; I- left hook; J-supra-anal plate, dorsal view; K- subgenital plate, ventral view. Scale bars: $1 \mathrm{~mm}$.

P. gajajimana is similar to P. japanna in term of the proportion of wings and body length, but differs in the following points. The body color of P. japanna is jet black, whereas $P$. gajajimana is smoky brown with strong redness. The wings of both male and female of $P$. gajajimana are short, and the tegmen of males just cover the abdominal posterior end slightly or almost the same length, while in the female, the tegmen is shorter, leaving the dorsal abdomen exposed. The supra-anal plate between the two species are morphologically similar, but the males of $P$. gajajimana have rounded corners at the tip of the plate. The subgenital plate of both species have two gentle protrusion at the center, but the gap between the two styles is smaller for P. gajajimana than P. japanna. The subgenital plate of the former on the whole is semicircular shape. The male genitalia of both species are very similar, but the L3d of P. japanna is uniformly thin after the distal protrusion, whereas $P$. gajajimana has the same thickness up to the distal protrusion and suddenly becomes very thin. In addition, the spine at the tip of $L 2 v$ in $P$. japanna is made up of two segments, but in P. gajajimana it 
is made up of one segment. Moreover, in P. gajajimana, the central spine of $L 2 \mathrm{v}$ is slender and 1.5 times longer than $P$. japanna.

Since the specimens are being kept as a colony in our laboratory, its reproductive biology, life-cycle, different stages of the nymphs and molecular identification, will be the subject of future studies. Follow-up investigation of specimens collected on December 2, 2018 from Akusekijima (N29.4609257 E129.6020881), which is located $50 \mathrm{~km}$ south of the original collection site, also revealed that the presence of $P$. gajajimana.

\section{Distribution}

Gajajima \& Akusekijima, Kagoshima-gun Toshimamura, Kagoshima Prefecture Japan.

Key to the species identification of genus Periplaneta found in Japan

1. Whole body tea brown in colour. Pronotum with yellowish brown or brownish black markings or circular markings

- - - - Whole body tea brown to black in colour. Pronotum has no conspicuous markings ... 4

2. Pronotum has yellow wheel pattern, among which there are the spectacle-like black marking. Anterior edge of the tegmen with conspicuous wide yellow stripestreaks..... P. australasiae (Fabricius, 1775) - - Pronotum with either yellow irregular streaks or wheel pattern surrounded by black to reddish brown streaks. Anterior edge of the tegmen with no yellow stripe streak

3. Whole of pronotum a mixture of brown and yellowish brown resulting in a dirty brown. Central area of the dorsal surface of the abdomen is light yellowish brown surrounded by blackish brown speckle. Supra anal plate of male turriform with few or no protrusion to the posterior

P. brunnea Burmeister, 1838

- - - - Pronotum with yellow wheel pattern surrounded by black to reddish brown streaks. Dorsal surface of the abdomen brown on the whole but not surrounded by brown speckle. Supra anal plate of male conspicuously protruded and divided by a deep cleft at the extremity...

P. americana (Linnaeus, 1758)

4. Pronotum, black to brownish black

- - - - Pronotum reddish brown. Body tea brown. In male, tegmen well-developed, extending beyond the abdomen. In female, tegmen short and end abruptly at around $7 \mathrm{~mm}$, with the abdomen extremity exposed

P. suzukii Asahina, 1977

5. Surface of pronotum is smooth and the body color is black to reddish brown. Tegmen well developed but may not reach the abdominal end

- - - - Pronotum not glossy, males are long and slender, and tegmen are well developed and extend beyond the abdominal extremity. Body surface with irregular undulation on the surface. Supra-anal plate of male rectangular with both lateral sides having saw-tooth structure at the posterior portion. Female with short wing, and its abdomen exposed P. japonica Karny, 1908

6. Tegmen well developed in both male and female and extends beyond the abdominal end. In male, corners of the supra anal plate almost quite sharp with distinct medial depression. Supra anal plate of female long and medial depression deep ................................ P. fuliginosa Serville, 1838 - - - - Tegmen of both males and females just reach the abdominal end or are shorter. Body color is jet black or reddish brown

7. The body color is jet black. Tegmen tip reach to almost the same position as the abdomen tip in both males and females P. japanna Asahina, 1969 - - - - Body color is reddish brown to blackish brown. Tegmen develops in both males and females, but in males, the tegmen tip reach the abdomen end or are slightly shorter. In the female, tegmen does not reach the abdominal end and exposes the abdomen beyond the 7 th abdominal plate P. gajajimana sp. nov.

\section{ACKNOWLEDGEMENTS}

We would like to express our gratitude to Mr. Shizuma Yanagisawa of Ryuyo Insect Nature Observation Park, who provided us with the information and samples of this species from Akusekijima.

\section{Conflict of interest}

The authors declare that they have no conflict of interest.

\section{REFERENCES}

Asahina, S. (1977). Blattaria or cockroaches of Amamioshima. In: Animals of Medical Importance in the Nansei Islands of Japan. Tokyo: Shinjuku Shobo, pp. 99-105.

Asahina, S. (1991). Blattaria of Japan. Tokyo: Nakayama Shoten Publisher, pp.1-253.

Bohn, H. (1984). Blatta forcata (Karny), The nearest relative of the Oriental cockroach (Blatta orientalis L.)(Insecta: Blattodea: Blattidae). Israel Journal of Zoology 33: 39-50. https://doi.org/10.1080/00212210.1984.10688554

Burmeister H. (1838). Handbuch der Entomologie. Theod. Chr. Friedr. Enslin, Berlin. Vol. 2, No. 2: i-viii; 397-756.

Komatsu, N., Ooi, H.K. \& Uchida, A. (2014). Sexual differentiation and developmental stage identification of the Indian cockroach, Pycnoscelus indicus (Blattodea: Blaberidae). Tropical Biomedicine 31: 828-835. https://drive.google.com/ file/d/0B75lcx0mfp2OSFBmS3ZicUZDVkk/view

Kumar, R. (1975). A review of the cockroaches of West Africa and the Congo Basin (Dictyoptera: Blattaria). Bulletin de I'Institut Fondamental d'Afrique Noire 37: 27-121.

Princis, K. (1966) Blattariae: Subordo Blattoidea. Fam.: Blattidae, Nocticolidae. In: Orthopterorum Catalogus. Pars 8. Beier, M. (editor). 's-Gravenhage: Dr. W. Junk, pp. 401614.

Princis, K. (1971) Blattariae: Subordo Epilamproidea: Fam.: Ectobiidae. In: Orthopterorum Catalogus. Pars 14. Beier, M. (editor). 's-Gravenhage: Dr. W. Junk N.V., pp. 1039-1224.

Roth, L.M. (1994). New Queensland cockroaches of Macrocerca Hanitsch and Periplaneta Burmeister (BLATTIDAE). Memoirs of the Queensland Museum 35: 225-233. https://www. cabdirect.org/cabdirect/abstract/19960500112

Roth, L.M. (1999). Descriptions of new taxa, redescriptions, and records of cockroaches, mostly from Malaysia and Indonesia (Dictyoptera: Blattaria). Oriental Insects 33: 109185. https://doi.org/10.1080/00305316.1999.10433789

Roth, L.M. (2003). Systematics and phylogeny of cockroaches (Dictyoptera: Blattaria). Oriental Insects 37: 1-186. https:// doi.org/10.1080/00305316.2003.10417344 